\title{
Immunological impression cytology of the conjunctival epithelium in patients with thyroid orbitopathy-related dry eye
}

\author{
S.L. Hsu ${ }^{1}$, P.Y. Lee ${ }^{1}$, C.H. Chang ${ }^{1}$ and C.H. Chen ${ }^{2,3}$ \\ ${ }^{1}$ Department of Ophthalmology, Kaohsiung Medical University Hospital, \\ Kaohsiung, Taiwan \\ ${ }^{2}$ Department of Medical Imaging and Radiological Sciences, \\ Central Taiwan University of Science and Technology, Taichung, Taiwan \\ ${ }^{3}$ Department of Medical Imaging and Radiological Sciences, \\ Kaohsiung Medical University, Kaohsiung, Taiwan \\ Corresponding authors: C.H. Chang / C.H. Chen \\ E-mail: cchncku@gmail.com
}

Genet. Mol. Res. 15 (3): gmr.15039011

Received July 21, 2016

Accepted August 1, 2016

Published August 30, 2016

DOI http://dx.doi.org/10.4238/gmr.15039011

Copyright (C) 2016 The Authors. This is an open-access article distributed under the terms of the Creative Commons Attribution ShareAlike (CC BY-SA) 4.0 License.

\begin{abstract}
Thyroid orbitopathy (TO) is an autoimmune disease that is complicated by ocular surface disorders, leading to discomfort. Dry eye is very prevalent in patients with TO. Recent studies on the pathogenesis of dry eye have focused on the inflammatory process, and some supporting evidence has been discovered. Because TO is a disorder of autoimmune origin, we assumed that the association between TO and dry eye is related to inflammation. Inflammation of the ocular surface in TO-related dry eye has not been well studied. In this study, we assessed cellular inflammation of the ocular surface and the cytokine profiles in patients with TO-related dry eye. Conjunctival impression cytology (CIC) was assessed with an immunofluorescent
\end{abstract}


assay. TO-related dry eye was diagnosed by using the Schirmer test, tear break-up time, thyroid function, and clinical signs. CIC was combined with immunological staining of interleukin- $1 \alpha$ (IL-1 $\alpha$ ), IL-1 $\beta$, and IL6 . The immunological impression cytology (IC) grade was compared to the clinical activity score of TO. All TO patients with dry eye were positive for IL- $1 \alpha$, IL-1 $\beta$, and IL-6. However, the normal controls were also positive for IL-1 $\alpha$. A trend was observed between the clinical inflammatory score and immunological IC grade. This study was the first to delineate the immunological IC of TO-related dry eye. Our study aimed to investigate the pathogenesis of dry eye in TO. Our findings suggest that the conjunctival cytokines IL- $1 \alpha$, IL-1 $\beta$, and IL- 6 may play a role. The results of this study will be useful for future studies of additional inflammatory cytokines, and the levels of these cytokines could be used as an outcome to assess the efficacy of treatment, such as anti-cytokine or immunosuppression therapy, in patients with TOrelated dry eye or other ocular surface inflammatory disorders.

Key words: Thyroid orbitopathy; Conjunctival impression cytology; Dry eye

\section{INTRODUCTION}

Thyroid orbitopathy (TO) is an autoimmune disease involving visual disturbances and orbital manifestations, which can cause severe proptosis, dry eyes, strabismus, and optic neuropathy (Bothun et al., 2009). The presence of dry eyes is the most frequent complaint in TO patients with ocular surface disorders in association with corneal exposure secondary to exophthalmos and lagophthalmos (Weetman, 1991; Burch and Wartofsky, 1993; Bartley et al., 1996; Boulos and Hardy, 2004). For visualization of the dry spots on the conjunctiva and cornea, both lissamine green and rose bengal, which have excellent staining ability, are preferable to fluorescein. The staining intensity scores for both of these stains were significantly high in TO-related dry eye, pointing to the presence of drying epithelial cells in patients with early and late TO (Stern et al., 2002).

Dry eye is an inflammatory disorder that affects the ocular surface, and proinflammatory cytokines have been increasingly suggested as possible mediators of lacrimal gland insufficiency (Zoukhri 2006). A previous study suggested that secretion of proinflammatory cytokines and matrix metalloproteinases (MMPs) by corneal epithelial cells promotes the development of ocular surface inflammation in dry eye syndrome (Boulos and Hardy, 2004), as desiccating stress stimulates the expression of MMP-9, interleukin- $1 \alpha$ (IL- $1 \alpha$ ), IL-1 $\beta$, and tumor necrosis factor-alpha (TNF- $\alpha$ ) in the corneal epithelium (Boulos and Hardy, 2004). Hyperosmolarity in dry eyes induced the release of IL-1 $\beta$, IL-6, TNF- $\alpha$, MMP-9, and IL-8 from corneal and conjunctival epithelial cells (Luo et al., 2005; Cavet et al., 2010).

The tear fluid in dry eyes has been shown to contain increased levels of proinflammatory cytokines, such as IL-1 (both IL- $1 \alpha$ and mature IL-1 $\beta$ ) and decreased levels of inactive IL-1 $\beta$ precursor (Boulos and Hardy, 2004). The conjunctival epithelium appears to be the source of the increased IL-1 detected in the tear fluid of patients with dry eyes (Boulos and Hardy, 2004). These results suggest that IL-1, and possibly other cytokines, may play important roles in the

Genetics and Molecular Research 15 (3): gmr.15039011 
pathogenesis of keratoconjunctivitis sicca or dry eye (Barton et al., 1998; Narayanan et al., 2008).

IL-1 $\beta$ can induce nitric oxide (NO) synthesis, which is related to cell death, in several secretory epithelial cell types (Beauregard and Brandt, 2003; Beauregard et al., 2003). In menopausal women, dry eye is related to a sex steroid deficiency and consequent fluidsecreting cell damage (Beauregard and Brandt, 2004). Estrogen was shown to increase the expression of IL-1 $\beta$, IL-6, and IL-8 in corneal epithelial cells, and this hormone may play an etiologic role in the ocular surface inflammation related to dry eye (Suzuki and Sullivan, 2005). It was shown that that cytokines in tear fluid could interfere with the synthesis of membraneassociated mucins (MUC-1, MUC-4, and MUC-16) in corneal epithelial cells (Jones et al., 1998; Blalock et al., 2008; Albertsmeyer et al., 2010), which can be clinically observed by rose bengal staining on the corneal surface.

In dry eye, upregulated expression of human leukocyte antigen-antigen D related (HLA-DR), which is induced by inflammation in epithelial cells, and apoptosis-related markers in conjunctival epithelial cells has been demonstrated (Brignole et al., 2000, 2001). Some researchers found increased levels of human beta-defensin-2 (hBD-2), which is induced by IL$1 \beta$ and TNF- $\alpha$, in the conjunctival epithelium of patients with moderate dry eye (Boulos and Hardy, 2004). In addition, decreased levels of IL-6 were noted in the conjunctival epithelium of patients with moderate to severe dry eye treated with $0.05 \%$ topical ophthalmic cyclosporine for 6 months (Turner et al., 2000). Next-generation cyclosporine A, which showed 4-fold inhibition of T-cell proliferation and proinflammatory cytokine release compared to those in the controls, was safe and effective in early clinical trials (Boulos and Hardy, 2004). Therefore, the conjunctival epithelium may be one of the sources of cytokine production.

Our hypothesis is that patients with TO-related dry eye have strong inflammation of the ocular surface. To test this hypothesis, we assessed ocular surface inflammation by calculating the inflammatory index using CIC and IFA. Knowledge of the cytokines expressed in different clinical situations will provide more clues about the pathogenesis of TO-related dry eye, a testable model for future research, and potential treatment targets.

\section{MATERIAL AND METHODS}

\section{Human subjects}

All the study patients were enrolled from the Outpatient Department of Ophthalmology at Kaohsiung Medical University Hospital. Patients with autoimmune disorders, conjunctivitis, or dry eye were excluded from the normal control group. The study was approved by the Institutional Review Board of Kaohsiung Medical University Hospital (KMUH-IRB-960252). The ethics IRBs approved the consent procedure. Written informed consent was obtained from all study participants, and consent was obtained from the guardians of minors enrolled in this study.

\section{Diagnosis of TO}

TO was diagnosed as hyperthyroidism with clinical eye signs, including proptosis, eyelid retraction, and restriction of ocular motility. Orbital inflammation was graded as the sum of clinical scores, including congestion ( 0 for negative, 1 for positive), conjunctival chemosis ( 0 for negative, 1 for positive, and 2 for overhanging chemosis), eyelid swelling ( 0 for negative, 1 for positive, and 2 for overhanging swelling), erythema ( 0 for negative, 1 for

Genetics and Molecular Research 15 (3): gmr.15039011 
positive), the presence of ocular motility pain ( 0 for negative, 1 for positive), and retrobulbar pressure ( 0 for negative, 1 for positive).

\section{Diagnosis of dry eye}

To diagnose dry eye, patients with TO complaining of dry eyes or observed to be congested with low tear meniscus, were assessed using Schirmer's test and tear break-up time (BUT).

\section{Schirmer test}

The test was performed after installation of topical anesthetic eye drops, followed by lightly blotting of the residual fluid in the inferior fornix. A Schirmer test paper strip $(5 \mathrm{~mm}$ wide, $35 \mathrm{~mm}$ long) was placed at the junction of the middle and lateral thirds of the lower eyelid of both eyes to minimize irritation to the cornea. The eyes were then closed to limit the effect of blinking. Aqueous tear production was quantified by measuring the amount of wetting. Less than $5 \mathrm{~mm}$ of wetting is highly suggestive of aqueous tear deficiency, while $5-10 \mathrm{~mm}$ is equivocal (Hikichi et al., 1995; Shrestha et al., 2011; Beckman et al., 2015; Courtin et al., 2016).

\section{Measurement of tear BUT}

Tear BUT was determined by instilling fluorescein into the inferior cul-de-sac and then evaluating precorneal tear film stability. It was measured prior to instillation of any eye drops and before the eyelids were manipulated in any way. The examiner moistened a fluorescein strip with sterile saline and applied it to the tarsal conjunctiva. After several blinks, the tear film was examined under a slit lamp with a blue filter, and the patient was asked not to blink. The timing of the appearance of the first randomly distributed dry spot of tear film is the tear BUT. A BUT of less than $10 \mathrm{~s}$ is considered abnormal (Brasche et al., 2001; Beckman et al., 2015; Courtin et al., 2016).

\section{Immunofluorescent cytokine staining of CIC}

CIC was performed as follows. With the patient in the supine position, $0.5 \%$ proparacaine (Alcaine) was instilled into the conjunctival sac. Then, the excess eye drops pooled in the conjunctival sac were gently swabbed. Cellulose acetate filter paper (Millipore membrane) was prepared $(3 \times 3 \mathrm{~mm})$. An impression of the four quadrants (temporal, upper, nasal, and lower) of the bulbar conjunctiva was obtained. One corner of the filter paper was grasped with blunt smooth-ended forceps, and the paper was gently pressed to stick it to the conjunctival surface. The filter paper was kept on the conjunctival surface for 3-5 s, and then peeled off. The paper was then applied to a clean glass slide coated with gelatin and the impression was transferred by applying gentle pressure. After fixation with $95 \%$ ethanol and $1 \%$ formalin, the slides were stained with hematoxylin-eosin and observed under a light microscope at low and high power (Boulos and Hardy, 2004).

The expression of IL-1 (IL-1 $\alpha$, precursor and mature IL-1 $\beta$ ) and IL-6 was evaluated in the CIC specimens. The membranes were stored at $-80^{\circ} \mathrm{C}$ until processing. They were fixed with cold methanol for $10 \mathrm{~min}$, and then blocked with phosphate buffered saline (PBS) containing $2 \%$ fetal bovine serum (FBS) for 20 min to block nonspecific staining. The primary antibodies against IL- $1 \alpha$, precursor and mature IL-1 $\beta$, and IL- 6 were used. The membrane

Genetics and Molecular Research 15 (3): gmr.15039011 
was incubated with the antibodies for $1 \mathrm{~h}$ at room temperature in a moist chamber. Then, the membranes were rinsed with PBS three times, and incubated with FITC-conjugated secondary antibody for $1 \mathrm{~h}$. Cytology specimens obtained from the inferior bulbar conjunctiva treated only with the secondary antibody served as a negative control. Membranes were washed with PBS three times, placed on a glass microscope slide, and then covered with non-fade mounting medium and a glass coverslip. Specimens were examined with a fluorescent microscope and photographed. The staining was scored as negative if the fluorescence intensity was less than or equal to that of the secondary antibody control. The staining was scored as positive if the intensity was greater than that of the control. Staining intensity was independently evaluated by two observers. To establish an experimental model of IFA, we applied these procedures to cultured human retinal pigment epithelial (RPE) cells obtained from American Type Culture Collection (ATCC). The human RPE cells were infected herpes simplex virus-1 (HSV-1) preIFA. The infected human RPE cells showed bright green fluorescence under a fluorescent microscope. In contrast, mock-infected human RPE cells showed no such fluorescence.

\section{Statistical analyses}

The chi-square test was used for statistical comparison of CIC IFA expression between the TO-related dry eye and normal control groups. A P value less than 0.05 was considered statistically significant.

\section{RESULTS}

The study included 39 TO patients with dry eye (12 males and 27 females). The mean age of the TO patient group was 48.5 years (range, $17-70$ years). The control group included 30 participants ( 6 males and 24 females). The mean age of the control group was 38.5 years (range, 22-64 years).

The brightness of fluorescence in the immunological CIC staining in TO patients with dry eye and the controls is shown in Figure 1. The immunofluorescence was graded on a scale from 0 to 3 according to intensity (Figure 2). The negative control, which was only treated with the secondary antibody, showed only trace immunofluorescence (Figure 2A) and was graded as 0 . Grade $1+$ showed faint fluorescence (Figure $2 \mathrm{~B}$ ), grade $2+$ showed bright fluorescence (Figure 2C), and grade 3+ showed diffuse, shiny fluorescence (Figure 2D). The fluorescence intensity greater than or equal to $1+$ was considered positive.

IL-1 $\alpha$ IFA expression was assessed in 16 TO patients with dry eye, including 3 males and 13 females (Table 1), and was graded as $0,1+, 2+$, and $3+$ in $3,3,8$, and 2 TO patients with dry eye, respectively. The positive rate ( $1+$ or higher) was $81.25 \%$ ( 3 grade $1+, 8$ grade $2+$, and 2 grade $3+$ ). IL-1 $\alpha$ IFA expression was also assessed in 15 control patients, including 4 males and 11 females. The positive rate was $86.67 \%$ (Table 1 ).

IL-1 $\beta$ IFA expression was assessed in 13 patients TO patients with dry eye, including 5 males and 8 females (Table 2), and was graded as $0,1+, 2+$, and $3+$ in $3,4,6$, and 0 patients, respectively. The positive rate was $76.92 \%$ (4 grade $1+$ and 6 grade $2+$ ). IL- $1 \beta$ IFA expression was also assessed in 15 control patients, including 2 males and 13 females, and the positive rate was only $13.33 \%$ (Table 2 ).

IL-6 IFA expression was assessed in 7 TO patients with dry eye, including 1 male and 6 females (Table 3 ), and the positive rate was $85.71 \%$ (4 Grade $1+$ and 2 Grade 2+).

Genetics and Molecular Research 15 (3): gmr.15039011 

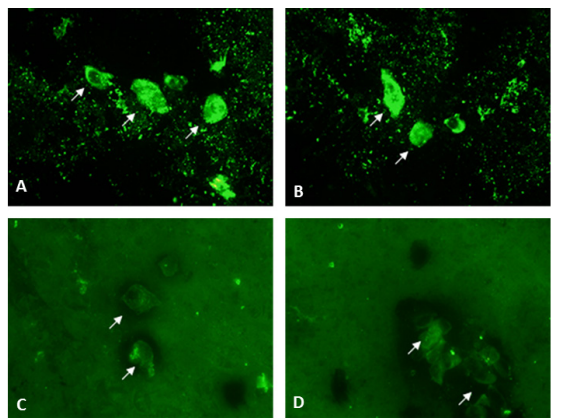

Figure 1. Immunofluorescence staining of IL-1 $\beta$ from immunological CIC in patients with TO-related dry eye and normal controls. IL-1 $\beta$ IFA expression: A. B. IL-1 $\beta$ IFA expression in patients with TO-related dry eye. The arrows indicate conjunctival cells with bright green fluorescence. C. D. IL-1 $\beta$ IFA expression in normal control subjects. The arrows indicate conjunctival cells with faint fluorescence compared to A and B.
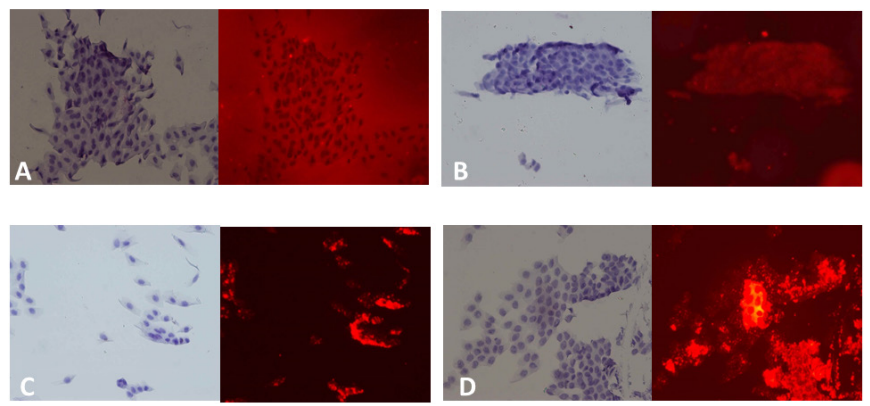

Figure 2. Immunofluorescence grading (from 0 to $3+$ ) based on fluorescence intensity. Grading of immunofluorescence (cytokine expression): A. grade 0, trace fluorescence; B. grade 1+, faint fluorescence; C. grade 2+, bright fluorescence; D. grade $3+$, diffuse and shiny fluorescence.

Table 1. IL-1 $\alpha$ IFA expression in patients with TO-related dry eye and normal controls.

\begin{tabular}{l|c|c|c|c}
\hline & Grade & Males (\%) & Females (\%) & Total (\%) \\
\hline \multirow{4}{*}{ Test group } & 0 & $1(6.25 \%)$ & $2(12.5 \%)$ & $3(18.75 \%)$ \\
\cline { 2 - 5 } & $1+$ & $0(0 \%)$ & $3(18.75 \%)$ & $3(18.75 \%)$ \\
\cline { 2 - 5 } & $2+$ & $1(6.25 \%)$ & $7(43.75 \%)$ & $8(50 \%)$ \\
\cline { 2 - 5 } & $3+$ & $1(6.25 \%)$ & $1(6.25 \%)$ & $2(12.5 \%)$ \\
\cline { 2 - 5 } & 0 & $0(0 \%)$ & $2(13.33 \%)$ & $2(13.33 \%)$ \\
\cline { 2 - 5 } & $1+$ & $4(26.27 \%)$ & $6(40 \%)$ & $3(20 \%)$ \\
\cline { 2 - 5 } & $2+$ & $0(0 \%)$ & $3(20 \%)$ & $0(0 \%)$ \\
\hline
\end{tabular}

Table 2. IL-1 $\beta$ IFA expression in patients with TO-related dry eye and normal controls.

\begin{tabular}{l|c|c|c|c}
\hline & Grade & Males (\%) & Females (\%) & Total (\%) \\
\hline \multirow{4}{*}{ Test group } & 0 & $0(0 \%)$ & $3(23.08 \%)$ & $3(23.08 \%)$ \\
\cline { 2 - 5 } & $1+$ & $2(15.38 \%)$ & $2(15.38 \%)$ & $4(30.77 \%)$ \\
\cline { 2 - 5 } & $2+$ & $3(23.08 \%)$ & $3(23.08 \%)$ & $6(46.15 \%)$ \\
\cline { 2 - 5 } & $3+$ & $0(0 \%)$ & $0(0 \%)$ & $0(0 \%)$ \\
\cline { 2 - 5 } & 0 & $2(13.33 \%)$ & $2(13.33 \%)$ & $2(13.33 \%)$ \\
\cline { 2 - 5 } & $1+$ & $0(0 \%)$ & $0(0 \%)$ & $0(0 \%)$ \\
\cline { 2 - 5 } & $2+$ & $0(0 \%)$ & $0(0 \%)$ & $0(0 \%)$ \\
\hline
\end{tabular}

Genetics and Molecular Research 15 (3): gmr.15039011 
Table 3. IL-6 IFA expression in patients with TO-related dry eye.

\begin{tabular}{l|c|c|c}
\hline Grade & Males (\%) & Females (\%) & Total (\%) \\
\hline 0 & $0(0 \%)$ & $1(14.29 \%)$ & $1(14.29 \%)$ \\
\hline $1+$ & $1(14.29 \%)$ & $3(42.86 \%)$ & $4(57.14 \%)$ \\
\hline $2+$ & $0(0 \%)$ & $2(28.57 \%)$ & $2(28.57 \%)$ \\
\hline $3+$ & $0(0 \%)$ & $0(0 \%)$ & $0(0 \%)$ \\
\hline
\end{tabular}

The immunological CIC grading was combined with the clinical inflammation score. The CIC for IL- $1 \alpha$ and IL-1 $\beta$ (Table 4 ) tended to show higher inflammation scores in patients with higher CIC grading.

We compared the IL- $1 \alpha$ and IL-1 $\beta$ IFA expression between the TO and control groups. The positive rates of IL-1 $\alpha$ IFA expression were not statistically significantly different between the two groups, but IL-1 $\beta$ IFA expression in the test group was significantly higher than that in the control group (Table 5).

The positive rates for IL- $1 \alpha$ expression were similar between the TO and normal control groups; therefore, the difference was not significant (Table 5). In the test group, we did not collect cases with an inflammation score of 7-8 (Table 4).

Table 4. IL-1 $\alpha$ (IL-1 $\beta$ ) impression cytology grade vs. TO inflammation score.

\begin{tabular}{|c|c|c|c|c|c|c|}
\hline & \multirow[t]{2}{*}{ CIC grade } & \multicolumn{4}{|c|}{ TO inflammation score } & \multirow{2}{*}{ Total } \\
\hline & & 0 & 1 to 3 & 4 to 6 & 7 to 8 & \\
\hline \multirow{4}{*}{$\overline{\mathrm{IL}}-1 \alpha$} & 0 & 1 & 1 & 0 & 0 & 2 \\
\hline & 1 & 0 & 5 & 2 & 0 & 7 \\
\hline & 2 & 0 & 4 & 5 & 0 & 9 \\
\hline & 3 & 0 & 1 & 2 & 0 & 3 \\
\hline \multirow[t]{4}{*}{$\overline{\mathrm{IL}-1 \beta}$} & 0 & 1 & 2 & 0 & 0 & 3 \\
\hline & 1 & 0 & 4 & 3 & 0 & 7 \\
\hline & 2 & 0 & 3 & 5 & 0 & 8 \\
\hline & 3 & 0 & 0 & 0 & 0 & 0 \\
\hline
\end{tabular}

CIC: conjunctiva impression cytology; TO: thyroid orbitopathy.

Table 5. Comparison of IL-1 $\alpha$ (IL-1 $\beta$ ) IFA expression in patients with TO-related dry eye and normal controls.

\begin{tabular}{l|l|c|c|c|c}
\hline \multicolumn{2}{l|}{} & Grade 0 (\%) & Positive (\%) & Total (\%) & P value \\
\hline \multirow{2}{*}{ IL-1 $\alpha$} & Test & $3(18.75 \%)$ & $13(81.25 \%)$ & $16(100 \%)$ & 0.9203 \\
\cline { 2 - 6 } & Control & $2(13.33 \%)$ & $13(86.67 \%)$ & $15(100 \%)$ & $0.0026^{*}$ \\
\hline \multirow{2}{*}{ IL-1 $\beta$} & Test & $3(23.08 \%)$ & $10(76.92 \%)$ & $13(100 \%)$ & $15(100 \%)$ \\
\cline { 2 - 6 } & Control & $13(86.67 \%)$ & $2(13.33 \%)$ & 1 & \\
\hline
\end{tabular}

$\mathrm{P}$ value was calculated by comparing the positive rate between the TO patients and controls using the chi-square test. *Statistically significant.

\section{DISCUSSION}

T cells play a central role in cell-mediated immunity, which is involved in dry eye and TO (Förster and Kahaly, 1998; Gopinath et al., 2009). T helper (Th) cells are activated after being presented with major histocompatibility complex (MHC) class II molecules by antigen presenting cells (APCs), and then the Th cells divide and secrete cytokines that regulate the immune reaction. Th cells can assist in the maturation of $\mathrm{B}$ cells and the activation of both cytotoxic T cells and macrophages. After activation, Th cells can differentiate into Th-1, Th-2, Th-3, and Th-17 subtypes. Studies have shown that Th-1 and Th-17 cells are correlated with

Genetics and Molecular Research 15 (3): gmr.15039011 
the pathogenesis of dry eye (Stern et al., 2005; Yoon et al., 2007; De Paiva et al., 2009; El Annan et al., 2009; Zheng et al., 2010).

IL-1 was first discovered in 1985. IL-1 $\alpha$ is constitutively produced by epithelial cells and can be secreted by other cells, including fibroblasts, mast cells, endothelial cells, monocytes, etc., upon stimulation. Thus, IL- $1 \alpha$ can be considered an epidermal cytokine. It has a central role in immune responses, and possesses metabolic, physiologic, and hematopoietic activities. IL-1 $\alpha$ interacts with many other cytokines, and the synergism between TNF and IL- $1 \alpha$ is most relevant, as they co-regulate some immune reactions, e.g., NO production and chemokine synthesis. In addition, IL-1 $\alpha$ can induce IL-2 and IL-6 secretion.

IL-1 $\beta$ is produced by activated macrophages as a proprotein that is proteolytically processed to its active form. IL-1 $\beta$ is important in inflammation, and it is involved in cell differentiation, proliferation, and apoptosis.

IL-6 is secreted by T cells and macrophages. It is also produced by muscle cells (myokine), adipocytes, and osteoblasts. It is important in trauma-induced inflammation and muscle contraction, and is an important mediator of fever during the acute phase response. In addition to its pro-inflammatory role, IL-6 also has anti-inflammatory effects, as an inhibitor of TNF- $\alpha$ and IL-1.

Inflammation has been implicated in both TO and dry eye. In our study, IL-1 $\alpha$, IL$1 \beta$, and IL- 6 were elevated in the conjunctival epithelial cells of patients with TO-related dry eye. However, IL-1 $\alpha$ was also expressed in the conjunctival epithelial cells of normal control patients. As IL-1 $\alpha$ is constitutively expressed in epithelial cells, the high positive rate in the control group might be indicative of the increased permeability of epithelial cells after laboratory treatment. This study is the first to investigate the cytokine alterations that occur in the conjunctival epithelial cells of patients with TO-related dry eye. In our study, we detected IL- $1 \alpha$, IL-1 $\beta$, and IL-6 expression in the conjunctival epithelial cells of patients with TOrelated dry eye. However, others did not find a significant increase in IL-1 $\beta$ levels in CIC samples with moderate dry eye (Narayanan et al., 2006).

Anti-cytokine therapy has been proposed for the treatment of TO (Paridaens et al., 2005; Cawood et al., 2006; Garrity and Bahn, 2006). However, there has been no discussion of the cytokines involved in dry eye associated with TO. In our study, we enrolled TO patients with dry eye and surveyed the expression of various cytokines, including IL- $1 \alpha$, IL- $1 \beta$, and IL-6, by CIC and IFA. Of the patients with TO-related dry eye, $76.92 \%$ were positive for IL-1 $\beta$ expression by immunofluorescence, compared to $13.33 \%$ of the control group. Patients with TO-related dry eye showed statistically significantly higher IL- $1 \beta$ expression in their conjunctival epithelium than normal patients. In contrast, similarly high positive immunofluorescent expression rates were noted for IL-1 $\alpha$ (81.25\%) and IL-6 (85.71\%). This implies that inflammation may be involved in the pathogenesis of dry eye associated with TO. In addition, anti-inflammatory or anti-cytokine therapy may be effective for the treatment of such cases (Brignole et al., 2000; Pflugfelder, 2004; De Paiva et al., 2006; Cordero-Coma et al., 2007; Kymionis et al., 2008; Pflugfelder et al., 2008; Ridder, 2008; Goyal et al., 2009; Gürdal et al., 2010). Anti-TNF- $\alpha$ agents, cytokine receptor antibodies, and IFN- $\alpha 2 a$ are the routinely used biologics (Jap and Chee, 2008).

One difficulty we encountered in the study was that an uncertain number of cells had adhered to the Millipore membrane in the CIC. The number of cells was usually not sufficient for further surveys. To avoid this problem, we suggest drying the conjunctival surface as much as possible before pressing the membrane on the conjunctiva, to promote cell adhesion.

Genetics and Molecular Research 15 (3): gmr.15039011 
Moreover, preparing more samples may guarantee sufficient specimens for survey. In the beginning of our study, we also planned to detect the cytokines via CIC and reverse transcriptase polymerase chain reaction (RT-PCR). However, the insufficient quantity of cells led to RT-PCR failure. In addition, releasing the adhered cells from the Millipore membrane was usually not easy. Therefore, detection of cytokines via CIC and IFA was a more promising procedure.

Our study had some limitations. First, we did not collect IF-6 IFA data from the control group. Thus, we could not compare IF-6 levels between the TO and control groups. Second, due to the limited group size, we did not collect cases of TO without dry eye. Because TO and dry eye both show ocular surface inflammation, we would have liked to compare cytokine expression between TO with and without dry eye.

Additional trials with staining for more cytokines in CIC from TO patients are needed. Further studies of cytokine expression comparing TO with and without dry eye, dry eye in association with TO and other causes, and TO-related dry eye to ocular surface inflammatory disorders. These methods could also be used to evaluate the effectiveness of different treatment regimens for dry eye, such as artificial tears, topical steroid eye drops, and topical ophthalmic cyclosporine $\mathrm{A}$ as well as various combinations thereof.

These data show that there are changes in some inflammatory indicators in TO-related dry eye. These indicators may be promising targets for future studies focused on the treatment for TO.

In our study, the conjunctival epithelium of patients with TO-related dry eye showed highly positive expression of IL-1 $\alpha$, IL-1 $\beta$, and IL-6. Therefore, we suggest that conjunctival cytokines play an important role in the pathogenesis of TO-related dry eye.

\section{Conflicts of interest}

The authors declare no conflict of interest.

\section{ACKNOWLEDGMENTS}

We thank the consulting service of the Department of Ophthalmology, Kaohsiung Medical University Hospital.

\section{REFERENCES}

Albertsmeyer AC, Kakkassery V, Spurr-Michaud S, Beeks O, et al. (2010). Effect of pro-inflammatory mediators on membrane-associated mucins expressed by human ocular surface epithelial cells. Exp. Eye Res. 90: 444-451. http:// dx.doi.org/10.1016/j.exer.2009.12.009

Bartley GB, Fatourechi V, Kadrmas EF, Jacobsen SJ, et al. (1996). Long-term follow-up of Graves ophthalmopathy in an incidence cohort. Ophthalmology 103: 958-962. http://dx.doi.org/10.1016/S0161-6420(96)30579-4

Barton K, Nava A, Monroy DC and Pflugfelder SC (1998). Cytokines and tear function in ocular surface disease. Adv. Exp. Med. Biol. 438: 461-469. http://dx.doi.org/10.1007/978-1-4615-5359-5_64

Beauregard C and Brandt PC (2003). Peroxisome proliferator-activated receptor agonists inhibit interleukin-1betamediated nitric oxide production in cultured lacrimal gland acinar cells. J. Ocul. Pharmacol. Ther. 19: 579-587. http://dx.doi.org/10.1089/108076803322660495

Beauregard C and Brandt P (2004). Down regulation of interleukin-1beta-induced nitric oxide production in lacrimal gland acinar cells by sex steroids. Curr. Eye Res. 29: 59-66. http://dx.doi.org/10.1080/02713680490513227

Beauregard C, Brandt PC and Chiou GC (2003). Induction of nitric oxide synthase and over-production of nitric oxide by interleukin-1beta in cultured lacrimal gland acinar cells. Exp. Eye Res. 77: 109-114. http://dx.doi.org/10.1016/ $\underline{\text { S0014-4835(03)00058-7 }}$

Genetics and Molecular Research 15 (3): gmr.15039011 
Beckman KA, Luchs J and Milner MS (2015). Making the diagnosis of Sjögren's syndrome in patients with dry eye. Clin. Ophthalmol. 10: 43-53.http://dx.doi.org/10.2147/OPTH.S80043

Blalock TD, Spurr-Michaud SJ, Tisdale AS and Gipson IK (2008). Release of membrane-associated mucins from ocular surface epithelia. Invest. Ophthalmol. Vis. Sci. 49: 1864-1871.http://dx.doi.org/10.1167/iovs.07-1081

Bothun ED, Scheurer RA, Harrison AR and Lee MS (2009). Update on thyroid eye disease and management. Clin. Ophthalmol. 3: 543-551.

Boulos PR and Hardy I (2004). Thyroid-associated orbitopathy: a clinicopathologic and therapeutic review. Curr. Opin. Ophthalmol. 15: 389-400.http://dx.doi.org/10.1097/01.icu.0000139992.15463.1b

Brasche S, Bullinger M, Bronisch M and Bischof W (2001). Eye- and skin symptoms in German office workers-subjective perception vs. objective medical screening. Int. J. Hyg. Environ. Health 203: 311-316. http://dx.doi. org/10.1078/1438-4639-00042

Brignole F, Pisella PJ, Goldschild M, De Saint Jean M, et al. (2000). Flow cytometric analysis of inflammatory markers in conjunctival epithelial cells of patients with dry eyes. Invest. Ophthalmol. Vis. Sci. 41: 1356-1363.

Brignole F, Pisella PJ, De Saint Jean M, Goldschild M, et al. (2001). Flow cytometric analysis of inflammatory markers in KCS: 6-month treatment with topical cyclosporin A. Invest. Ophthalmol. Vis. Sci. 42: 90-95.

Burch HB and Wartofsky L (1993). Graves' ophthalmopathy: current concepts regarding pathogenesis and management. Endocr. Rev. 14: 747-793.

Cavet ME, Harrington KL, Ward KW and Zhang JZ (2010). Mapracorat, a novel selective glucocorticoid receptor agonist, inhibits hyperosmolar-induced cytokine release and MAPK pathways in human corneal epithelial cells. Mol. Vis. 16: $1791-1800$

Cawood TJ, Moriarty P, O'Farrelly C and O'Shea D (2006). The effects of tumour necrosis factor-alpha and interleukin1 on an in vitro model of thyroid-associated ophthalmopathy; contrasting effects on adipogenesis. Eur. J. Endocrinol. 155: 395-403.http://dx.doi.org/10.1530/eje.1.02242

Cordero-Coma M, Anzaar F, Sobrin L and Foster CS (2007). Systemic immunomodulatory therapy in severe dry eye secondary to inflammation. Ocul. Immunol. Inflamm. 15: 99-104.http://dx.doi.org/10.1080/09273940701299354

Courtin R, Pereira B, Naughton G, Chamoux A, et al. (2016). Prevalence of dry eye disease in visual display terminal workers: a systematic review and meta-analysis. BMJ Open 6: e009675. http://dx.doi.org/10.1136/bmjopen-2015-009675

De Paiva CS, Corrales RM, Villarreal AL, Farley WJ, et al. (2006). Corticosteroid and doxycycline suppress MMP-9 and inflammatory cytokine expression, MAPK activation in the corneal epithelium in experimental dry eye. Exp. Eye Res. 83: 526-535.http://dx.doi.org/10.1016/j.exer.2006.02.004

De Paiva CS, Chotikavanich S, Pangelinan SB, Pitcher JD, 3rd, et al. (2009). IL-17 disrupts corneal barrier following desiccating stress. Mucosal Immunol. 2: 243-253.http://dx.doi.org/10.1038/mi.2009.5

El Annan J, Chauhan SK, Ecoiffier T, Zhang Q, et al. (2009). Characterization of effector T cells in dry eye disease. Invest. Ophthalmol. Vis. Sci. 50: 3802-3807.http://dx.doi.org/10.1167/iovs.08-2417

Förster G and Kahaly G (1998). [Endocrine orbitopathy 1998]. Med. Klin. (Munich) 93:365-373.http://dx.doi.org/10.1007/ BF03044681

Garrity JA and Bahn RS (2006). Pathogenesis of graves ophthalmopathy: implications for prediction, prevention, and treatment. Am. J. Ophthalmol. 142: 147-153.e2.http://dx.doi.org/10.1016/j.ajo.2006.02.047

Gopinath B, Wescombe L, Nguyen B and Wall JR (2009). Can autoimmunity against calsequestrin explain the eye and eyelid muscle inflammation of thyroid eye disease? Orbit 28: 256-261.http://dx.doi.org/10.1080/01676830903104629

Goyal S, Chauhan SK, Zhang Q and Dana R (2009). Amelioration of murine dry eye disease by topical antagonist to chemokine receptor 2. Arch. Ophthalmol. 127: 882-887. http://dx.doi.org/10.1001/archophthalmol.2009.125

Gürdal C, Genç I, Saraç O, Gönül I, et al. (2010). Topical cyclosporine in thyroid orbitopathy-related dry eye: clinical findings, conjunctival epithelial apoptosis, and MMP-9 expression. Curr. Eye Res. 35: 771-777. http://dx.doi.org/10 $.3109 / 02713683.2010 .490320$

Hikichi T, Yoshida A, Fukui Y, Hamano T, et al. (1995). Prevalence of dry eye in Japanese eye centers. Graefes Arch. Clin. Exp. Ophthalmol. 233: 555-558. http://dx.doi.org/10.1007/BF00404705

Jap A and Chee SP (2008). Immunosuppressive therapy for ocular diseases. Curr. Opin. Ophthalmol. 19: 535-540. http:// dx.doi.org/10.1097/ICU.0b013e3283126d20

Jones DT, Monroy D, Ji Z and Pflugfelder SC (1998). Alterations of ocular surface gene expression in Sjögren's syndrome. Adv. Exp. Med. Biol. 438: 533-536. http://dx.doi.org/10.1007/978-1-4615-5359-5_75

Kymionis GD, Bouzoukis DI, Diakonis VF and Siganos C (2008). Treatment of chronic dry eye: focus on cyclosporine. Clin. Ophthalmol. 2: 829-836.http://dx.doi.org/10.2147/OPTH.S1409

Luo L, Li DQ, Corrales RM and Pflugfelder SC (2005). Hyperosmolar saline is a proinflammatory stress on the mouse ocular surface. Eye Contact Lens 31: 186-193. http://dx.doi.org/10.1097/01.ICL.0000162759.79740.46

Genetics and Molecular Research 15 (3): gmr.15039011 
Narayanan S, Miller WL and McDermott AM (2006). Conjunctival cytokine expression in symptomatic moderate dry eye subjects. Invest. Ophthalmol. Vis. Sci. 47: 2445-2450. http://dx.doi.org/10.1167/iovs.05-1364

Narayanan S, Corrales RM, Farley W, McDermott AM, et al. (2008). Interleukin-1 receptor-1-deficient mice show attenuated production of ocular surface inflammatory cytokines in experimental dry eye. Cornea 27: 811-817.http:// dx.doi.org/10.1097/ICO.0b013e31816bf46c

Paridaens D, van den Bosch WA, van der Loos TL, Krenning EP, et al. (2005). The effect of etanercept on Graves' ophthalmopathy: a pilot study. Eye (Lond.) 19: 1286-1289.http://dx.doi.org/10.1038/sj.eye.6701768

Pflugfelder SC (2004). Antiinflammatory therapy for dry eye. Am. J. Ophthalmol. 137: 337-342. http://dx.doi.org/10.1016/j. ajo.2003.10.036

Pflugfelder SC, De Paiva CS, Villarreal AL and Stern ME (2008). Effects of sequential artificial tear and cyclosporine emulsion therapy on conjunctival goblet cell density and transforming growth factor-beta2 production. Cornea 27: 64-69. http://dx.doi.org/10.1097/ICO.0b013e318158f6dc

Ridder WH, 3rd (2008). Ciclosporin use in dry eye disease patients. Expert Opin. Pharmacother. 9: 3121-3128. http:// dx.doi.org/10.1517/14656560802500613

Shrestha GS, Mohamed FN and Shah DN (2011). Visual problems among video display terminal (VDT) users in Nepal. J. Optom. 4: 56-62. http://dx.doi.org/10.1016/S1888-4296(11)70042-5

Stern ME, Gao J, Schwalb TA, Ngo M, et al. (2002). Conjunctival T-cell subpopulations in Sjögren's and non-Sjögren's patients with dry eye. Invest. Ophthalmol. Vis. Sci. 43: 2609-2614.

Stern ME, Siemasko KF, Gao J, Calonge M, et al. (2005). Evaluation of ocular surface inflammation in the presence of dry eye and allergic conjunctival disease. Ocul. Surf. 3 (Suppl): S161-S164. http://dx.doi.org/10.1016/S1542$\underline{0124(12) 70246-X}$

Suzuki T and Sullivan DA (2005). Estrogen stimulation of proinflammatory cytokine and matrix metalloproteinase gene expression in human corneal epithelial cells. Cornea 24: 1004-1009. http://dx.doi.org/10.1097/01. ico.0000160973.04072.a5

Turner K, Pflugfelder SC, Ji Z, Feuer WJ, et al. (2000). Interleukin-6 levels in the conjunctival epithelium of patients with dry eye disease treated with cyclosporine ophthalmic emulsion. Cornea 19: 492-496. http://dx.doi. org/10.1097/00003226-200007000-00018

Weetman AP (1991). Thyroid-associated eye disease: pathophysiology. Lancet 338: 25-28.http://dx.doi.org/10.1016/01406736(91)90013-F

Yoon KC, De Paiva CS, Qi H, Chen Z, et al. (2007). Expression of Th-1 chemokines and chemokine receptors on the ocular surface of C57BL/6 mice: effects of desiccating stress. Invest. Ophthalmol. Vis. Sci. 48: 2561-2569. http:// dx.doi.org/10.1167/iovs.07-0002

Zheng X, de Paiva CS, Li DQ, Farley WJ, et al. (2010). Desiccating stress promotion of Th17 differentiation by ocular surface tissues through a dendritic cell-mediated pathway. Invest. Ophthalmol. Vis. Sci. 51: 3083-3091. http://dx.doi. org/10.1167/iovs.09-3838

Zoukhri D (2006). Effect of inflammation on lacrimal gland function. Exp. Eye Res. 82: 885-898. http://dx.doi. org/10.1016/j.exer.2005.10.018

Genetics and Molecular Research 15 (3): gmr.15039011 